\title{
o começo do terrível - o legado de von Martius entre a ciência e a ficção na representação da natureza brasileira
}

\section{GABRIELA REINALDO}

\section{Resumo}

Desde a chegada dos primeiros europeus em terras

brasileiras, a representação imagística do Brasil oscila entre o paraíso terreal e o bestiário do medievo. Com a abertura dos portos às nações estrangeiras, cientistas-artistas percorrem o Brasil e inauguram um novo tipo de visualidade ligado aos paradigmas científicos do século XIX, que recusavam aproximações com a especulação fantasiosa. Este artigo discorre sobre o legado do botânico bávaro Carl Friedrich Philipp von Martius. Interessa-nos discorrer sobre como sua representação da natureza confunde ciência e ficção e se aproxima do sublime kantiano.

Palavras-chave:

Carl Friedrich Philipp von Martius, sublime, arte-ciência 


\section{The beginning of the terror - the legacy of von Martius between science and fiction in the representation of the Brazilian nature}

\section{GABRIELA REINALDO}

\section{Abstract}

As the harbors were opened to foreign nations, scientistsartists went through Brazilian lands and initiated a new kind of visuality connected to scientific paradigms of the nineteenth century, which rejected approaches with the fanciful speculation. This article is about the botanical legacy of the Bavarian Carl Friedrich Philipp von Martius.

Keywords: Carl Friedrich Philipp von Martius, sublime, art-science It matters to us to expatiate on how his representation of nature approaches the Kantian sublime and blends into science and fiction. 
O

presente artigo dedica-se a discorrer sobre o legado do botânico e naturalista Carl Friedrich Phillip von Martius, que viveu de 1817 a 1820 no Brasil, tendo percorrido cerca de dez mil quilômetros, passando pelos estados do Rio de Janeiro, São Paulo, Minas Gerais, Goiás, Bahia, Pernambuco, Piauí, Maranhão e Pará com o intuito de recolher espécimes e informações sobre o país a pedido do rei Maximiliano José I da Baviera. Von Martius, assim como seus contemporâneos, artistas-cientistas que aportaram no Brasil após a abertura dos portos às nações estrangeiras no início do século XIX, contribui para mudanças nos paradigmas de visualidade que retratam o Brasil desde a chegada dos primeiros europeus.

Embora atento à ciência de seu tempo, que predicava um fazer científico isento de subjetividades, na obra de Martius há momentos em que o autor mistura ciência e ficção, apuro documental e observações idiossincráticas. Nosso objetivo é analisar algumas das Tabulae Phisiognomicae, pranchas que combinam imagem e texto e que fazem parte da obra Flora Brasiliensis, de modo a perceber as correspondências entre o conceito de sublime de I. Kant e a produção de Martius. Para tanto, discorreremos sobre os contextos históricos e culturais nos quais se situavam o autor e a obra para, então, passarmos à análise do conteúdo das Tabulae selecionadas.

\section{A reinvenção do Brasil}

O Brasil é retratado desde seu descobrimento. Relatos de quem aqui pisou e transcreveu (não sem fantasiar) o vivido e relatos de quem nunca chupou um caju ou se deparou com uma cobra coral. Quanto aos costumes dos nativos, o assombro com a prática do canibalismo é a própria concretização de um dos medos mais ancestrais e atávicos do homem. Um 

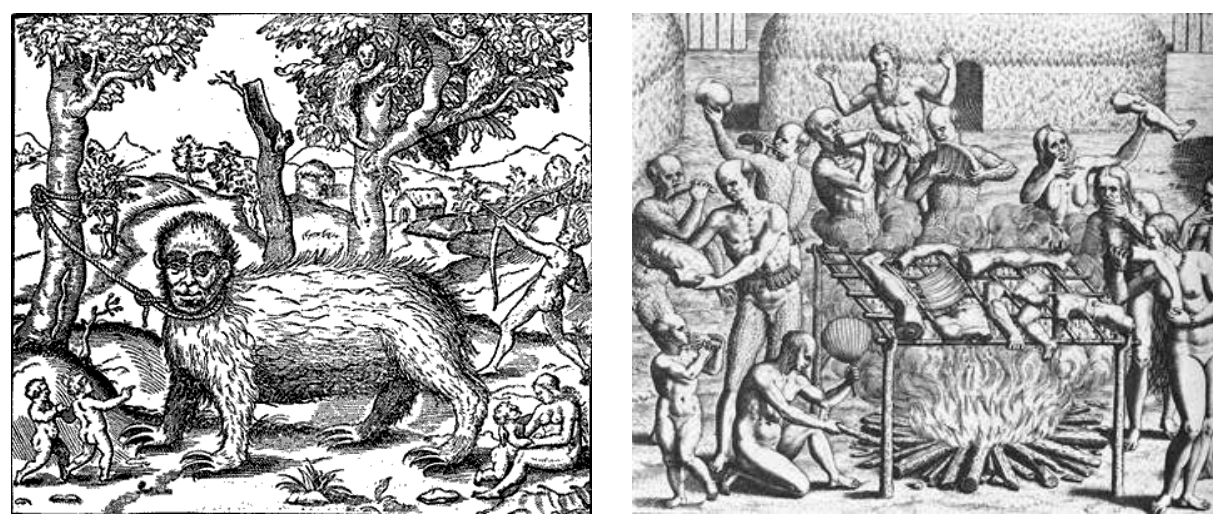

Figura 1

ANDRÉ THEVET. Haut, Beste qui Vit de Vent. Xilogravura, 13,4 $x$ 15,6 cm. Ilustração do livro La cosmographie universelle..., Paris, Guillaume Chaudiere, 1575. Vol. 2, p. 241. Biblioteca Municipal de São Paulo Mario de Andrade, São Paulo, Brasil.

Figura 2

Theodore De Bry. Staden presenciando uma cena de canibalismo. “Americae Tertia Pars...”. Ilustração do relato das viagens de Hans Staden ao Brasil. Biblioteca Municipal Mario de Andrade, São Paulo, Brasil.

mundo de canibais e de fauna e flora igualmente exuberantes e estranhas. Mundo inaudito que fissura a laca do Renascimento deixando brotar dessa fenda monstros e fantasmas que já pareciam adormecidos na noite escura do medievo.

Carl Friedrich Philipp von Martius chega ao Brasil 300 anos depois de Thevet (figura 1), Staden e das famosas criaturas estereotipadas de De Bry (figura 2). O país que nasceu para o mundo europeu como um híbrido indecifrável - éden na terra ou testemunho de potências infernais -, no século XIX, é examinado pelas lentes da ciência. Além dos artistas que o acompanham, cujas obras ilustram seus livros, na época de Martius era comum que os próprios naturalistas fossem dotados de aptidões para o desenho. Estas ilustrações, embora possam atender a uma finalidade estética, orientavam-se essencialmente para a preservação da memória visual das expedições (BELLUZZO, 1994). Imagem e palavra que marcam a própria concepção da história natural, que se alicerça na representação, na possibilidade de nomear, como afirma Foucault (1966).

No século XIX, os modos de produção de conhecimento divergem quanto à importância do trabalho de campo ou o chamado "saber de gabinete" (KURY, 20o1). De um lado, postava-se Georges Cuvier (1769-1832), que acreditava que excursões para o registro in loco distrairia o pesquisador e o afastaria da sistematicidade que o objeto requeria, e, do outro, pesquisadores que seguiriam a tradição de Alexander von Humboldt, para quem as impressões estéticas fazem parte da atividade científica (HUMBOLDT, 1995; 1997). Viajar, além dos perigos ligados às precárias condições de transporte e ao risco de contrair doenças tropicais, era desaconselhável, uma vez que não havia unanimidade quanto à valorização do cientista-viajante junto à comunidade acadêmica. 
Recusando o papel de pesquisador de gabinete, a produção de Martius tem início no lombo balançante das mulas, que ora corroboram ora inventam estradas, e na flutuação das canoas, que adentram os rios brasileiros enfrentando chuvas e sedes, febres, insetos, cobras e noites no sereno. Traços que posteriormente serão reelaborados com alguns anos e muitas milhas de distância, já na Alemanha onde conhecem a litogravura, recém elaborada por Senefelder nos últimos anos do século XVIII, que se mostra a técnica mais apropriada para o projeto de produção de imagens do Flora Brasiliensis.

Martius é contemporâneo de Goethe, que se revela entusiasmado pela sua empreita e pelo estilo de sua escrita. Em Zur Naturwissenschaft überhaupt, besonders zur Morphologie, Goethe congratula Martius e Spix por oferecerem aos leitores europeus informações in loco sobre um universo desconhecido que preenchem a imaginação e memória. $\mathrm{O}$ interesse pela botânica, pela filosofia e pela literatura, os aproxima. A correspondência ${ }^{1}$ mantida por nove anos - e interrompida apenas com a morte de Goethe - tem início em 1823, portanto três anos depois do retorno de Martius à Europa (LISBOA, 1997). Além de Goethe, Martius é herdeiro da Naturphilosophie (Filosofia da Natureza) de Schelling, que acreditava que a natureza não era uma massa inerte, mas uma inteligência incessante e eterna em seu brotar, fenecer e renascer que dá origem a tudo o que existe; e, como os viajantes do seu tempo, era um entusiasta das ideias de Humboldt (LISBOA, 1997; BELLUZZO, 1994; KURY, 2001; PEDRAS, 2000) que, embora tenha contornado a América Latina, não teve permissão para adentrar o Brasil ${ }^{2}$.

Com a abertura dos portos às nações estrangeiras, artistas, comerciantes, farmacêuticos, biólogos, botânicos e aventureiros tem a entrada autorizada e expedições avançam na direção dos grotões do país. 1808 é o ano da chegada da corte portuguesa ao Brasil e da abertura dos portos às nações amigas que marcaria o fim da exclusividade portuguesa na exploração dos recursos naturais brasileiros. Neste momento, o Brasil é visitado por várias missões, dentre elas a missão austríaca, que acompanha a arquiduquesa Dona Leopoldina, que se casará com o príncipe herdeiro do Reino Unido de Portugal, Brasil e Algarves, D. Pedro. Flora Brasiliensis 3 , a obra mais grandiosa de Martius com 2.253 gêneros e 3.811 estampas reunidos em 15 volumes, divididos em 40 partes, com um total de 10.367 páginas ${ }^{4}$, é resultado dessa excursão. Produzida entre 1840 e 1906 - período que ultrapassa o tempo de vida de Martius5, que dedica seus últimos quarenta anos inteiramente à elaboração 
do material coletado em sua excursão pelo Brasil - por von Martius, August Wilhelm Eichler e Ignatz Urban, com a participação de 65 especialistas de vários países, contém tratamentos taxonômicos de 22.767 espécies, a maioria de angiospermas brasileiras.

O primeiro volume do Flora Brasiliensis compreende 59 Tabulae Physiognomicae 6 e é o primeiro ensaio sobre a fitogeografia do Brasil. As Tabulae Physiognomicae abrem o Flora Brasiliensis, dão boas vindas ao leitor. Além de oferecer uma visão ampliada e genérica de diversas partes do Brasil, o texto das Tabulae é convidativo, cria uma introdução abrangente, ilustrativa e facilitadora do texto excessivamente técnico, austero, com as terminologias em latim, que viria em seguida nos outros 39 densos volumes da obra. Nesse ensaio fitogeográfico, Martius esboça cinco regiões geográficas brasileiras (que hoje correspondem ao conceito atual de domínios fitogeográficos) que seriam o cerrado, a caatinga, o pantanal a as florestas Amazônica e Atlântica.

Além da fauna e da flora, as imagens de autoria de Thomas Ender, Benjamin Mary, Johan Jacob Steinmann, de um seguidor de Rugendas (Martius não chega a dizer seu nome), Dr. Estevão $0^{7}$, do fotógrafo suíço George Leuzinger, dos litógrafos F. Hohe e August Brandmueller ${ }^{8}$ e do próprio Martius detalham também, ainda que sem a mesma ênfase dada à natureza, tipos físicos e suas atividades nos ambientes ilustrados. Com as Tabulae Martius pretendia fazer com que os leitores pudessem observar não apenas os arbustos e árvores individualmente e que nascem de forma aleatória - intenção que derivava do pensamento humboldtiano -, mas que pudesse ter uma noção da massa verde, da combinação entre vegetação, animais e clima: "o que dá a cada lugar uma certa cor festiva e que, como na verdade ninguém ignora, varia imensamente nas diversas regiões do Brasil" (MARTIUS, 1996: 23), explica em nota introdutória.

\section{A nomeação do visível}

L'histoire naturelle, ce n'est rien d'autre que la nomination du visible. (Michel Foucault, Les mots et les choses - une archéologie des sciences humaines).

Nature reflected in art always reflects the artist's own mind, his predilections, his enjoyments and therefore his moods (Ernst Gombrich, The Story of Art). 
O papel da imagem na observação e estudos da natureza é imemorial, desde que se considere que os primeiros registros humanos não apenas a tinham como temática - seja na forma geometricamente estilizada ou naturalisticamente imitativa assim como provinham do mundo natural os instrumentos que produziam essas imagens, fossem galhos, pedaços de ossos, de chifres ou pedras. De origem animal, como sangue, tecidos ósseos, peles, cartilagens ou excrementos; vegetal, como raízes, folhas, flores e frutos; ou mineral, também a manipulação dos pigmentos é resultado de uma solidariedade telúrica, de um conhecimento profundo e empírico da biologia e da química dos elementos. Além das plásticas, as danças, os cânticos, os rituais, as lutas e o teatro - atividades que igualmente compreendem imagens (sonoras, táteis e cinestésicas ou proprioceptivas) - sempre estiveram em correspondência mimética com os movimentos e sons dos animais, das plantas, dos rios, do fluxo das estações e com as condições meteorológicas.

Afusando o feixe dessas representações para a descrição botânica, podemos dizer que o interesse farmacológico, ornamental ou ritualístico pelas plantas e o seu registro está presente em quase todas as culturas, em diferentes eras, o que fez com que o seu desenho acompanhado da descrição textual de suas características se estendesse por praticamente todo o globo. Entretanto, mesmo com toda essa imprecisão temporal e geográfica, é possível mapear alguns marcos em que a catalogação botânica aconteceu de forma mais sistemática. Historicamente ligados à farmacologia, os livros de ilustração botânica seguem a tradição iniciada por Theophrastus (371/370 - 287/286 A.C.) (figura 3), discípulo de Aristóteles e seu sucessor direto na escola peripatética. Assim como Aristóteles procede com a zoologia, coletando e catalogando informações, Theophrastus faz com o mundo vegetal (TOUWAIDE, 2010). Pode-se ainda incluir no rol da chamada "botânica antiga" Naturalis Historia, de Plínio (23-74 A.D.) e De simplicium medicamentorum temperamentis et facultatibus, de Galeno de Pergamon (129-217 A.D.). Galeno de Pergamon, ainda que não tenha escrito um tratado devotado à botânica, revisa De Materia Medica de Dioscorides ${ }^{9}$ - este sim um dos tratados de maior repercussão na Idade Antiga tardia, Medievo e Renascença (figura 4).

Deitar na folha do papel uma realidade tridimensional, poliédrica, breve e que não se repete requeria do ilustrador, que na maioria das vezes era também naturalista e/ou jardineiro, apuro estético e um senso agudo de observação empírica. 

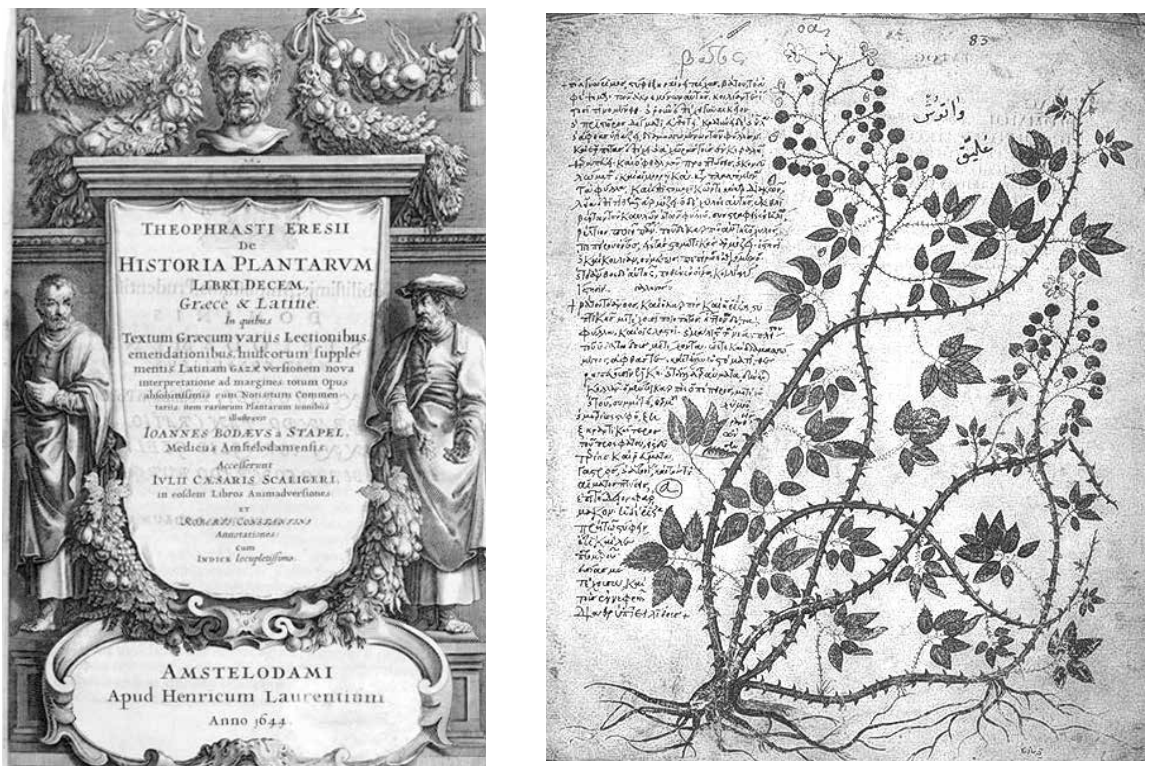

Figura 3

Theophrastus. Frontispiece to the illustrated 1644 edition of the Enquiry into Plants

Figura 4 Vienna Dioscurides. Data 515 A.D. Public domain
Acima de tudo é um trabalho de tradução intersemiótica que além da elaboração imagética que dá contornos bidimensionais às formas da natureza também se articula com as palavras que pareiam os desenhos. Esclarecemos que nos valemos aqui do conceito de signo peirceano, composto pela tríade representamen, objeto e interpretante, que só existe como processo sígnico de produção de sentido, de semiose. Semiose, para Peirce, é sinônimo de tradução, de interpretação, de pensamento de signo. Se é infinita é porque seu interpretante não encontra sossego. Ao invés de apontar para uma significação única, desemboca num conjunto de possíveis que medeiam apesar de o interpretante ser o terceiro correlato da tríade, ele se enverga para o meio - a relação entre o signo e o seu objeto.

Essa ideia é abordada, de outros modos, por I. Lotman (1996; 2000), que dirá que a intraduzibilidade cultural é inerente aos processos tradutórios, e R. Jakobson (1975), que pontua a tradução intersígnica como um tipo de tradução que articula sistemas verbais e não verbais. Argumentos que sustentam as reflexões de Julio Plaza (2003) e Haroldo de Campos (2006), para quem a tradução será sempre transcriação.

Como tradução entre sistemas sígnicos que enredam diferentes códigos e linguagens, os manuais e livros de botânica estarão sempre sujeitos à materialidade dos objetos, às condições históricas de seu tempo e às faculdades intelectuais e habilidades do seu realizador. Nesse sistema, embora a imagem desem- 

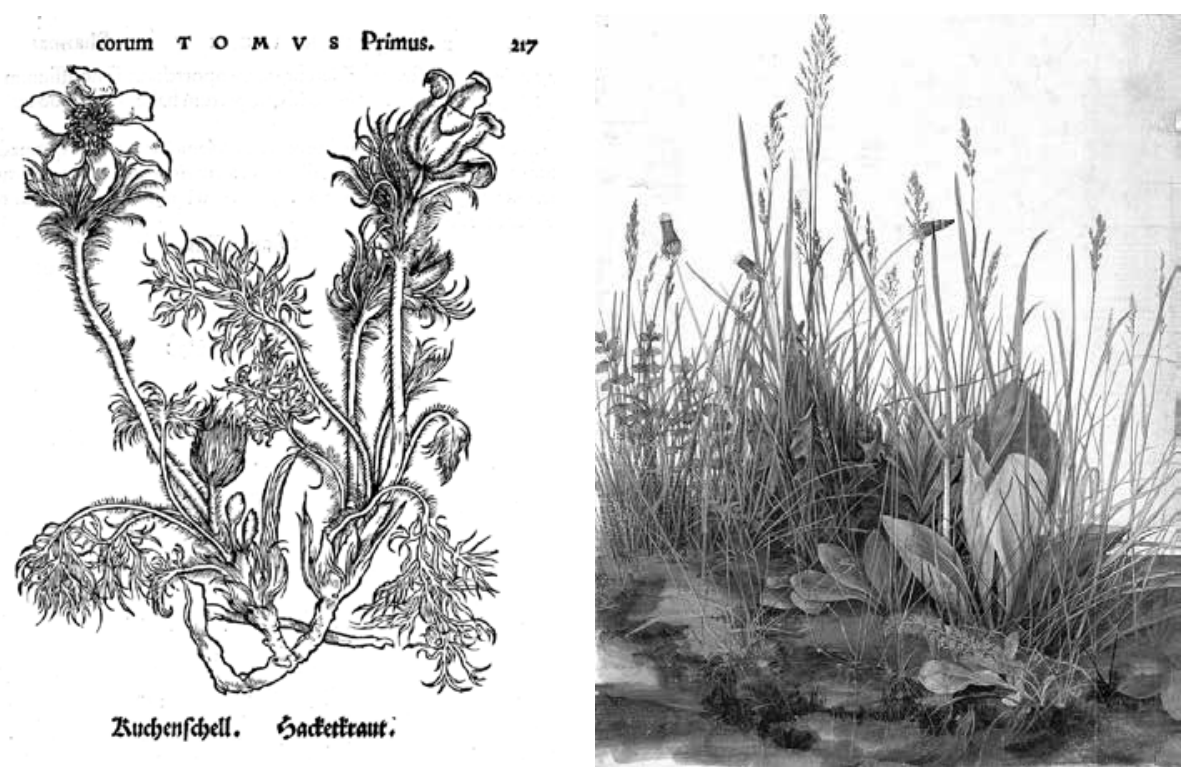

penhe um papel fundamental no estudo da botânica, os textos que acompanhavam esses desenhos historicamente costumavam receber os créditos pelo trabalho científico, relegando a imagem a um papel secundário de mera estampa ilustrativa.

Neste sentido, é sintomático que a primeira impressão reconhecida como científica anterior ao 160o, o Herbarum vivae eicones (figura 5), publicado em Estrasburgo entre 1532 e 1536, tenha sido atribuída a Otto Brunfels (1488-1534) em detrimento da importância da coautoria de Hans Weiditz (1495-1536). Sabe-se, contudo, que Brunfels se ressentia do excesso de entusiasmo que o público devotava aos desenhos de Weiditz, atenção que ele considerava imerecida uma vez que seu texto se assentava em "autoridades clássicas" enquanto que o trabalho de Weiditz se valia, na sua opinião, "apenas" de um senso (extremamente) apurado de observação e destreza técnica (SMITH, 2010). O artesanato científico de Weiditz se situa na terceira geração estudos da natureza na Alemanha, precedido imediatamente por Albrecht Dürer (figura 6). Dürer ligavase aos experimentos de Martin Schongauer, cujos desenhos, dando continuidade aos mestres flamencos com quem havia estudado e a uma tradição familiar de ourivesaria, davam mostras de uma intensa atenção para os detalhes da natureza criando uma nova ilusão pictórica.

Ou seja, nem o Herbarum vivae eicones nem o De Historia stirpium commentarii insignies, publicado uma década
Figura 5

Pasqueflower, from Otto Brunfels, Herbarum, 1530-32. Herbarum Vivae Eicones ad Nature Imitationem.

Strassburg: apud Joannem Schottu[m], 1530-1532

Figura 6

Albrecht Dürer.

In German: Das große Rasenstück (The Large Piece of Turf). Watercolor and body color, heightened with white body color. 1503. $42.8 \times 31.5 \mathrm{~cm}$ $(16.9 \times 12.4 \mathrm{in}) 10$ 


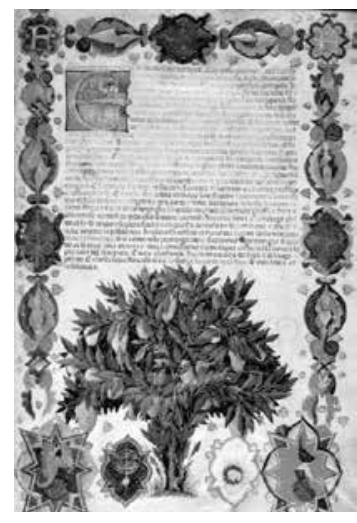

Figura 7

Serapion the Younger, translation of the herbal (the Carrara Herbal), including Liber agrega, Herbolario volgare; De medicamentis, with index (ff. 263-265). Italy, N. (Padua). between c. 1390 and 1404. Scribe: Jacopo Filippo ${ }^{12}$ depois por Leonhart Fuchs (1501-1566), teriam sido possíveis sem a tradição dos trabalhos do norte da Europa de estudos da natureza. Qual um uroborus engolindo a própria cauda, há uma circularidade histórica envolvendo Holanda, Alemanha, o chamado "mundo árabe" e a Itália, uma vez que a tradição holandesa que apura o olhar para o mundo natural e refina as práticas de reprodução, por sua vez, deitam suas raízes em um livro de botânica, o Carrara Herbal (KALY, 2010; SMITH, 2010; TOUWAIDE, 2010) (figura 7), que também é resultado do entrelace de diferentes matrizes culturais. A obra, hoje pertencente ao acervo da British Library" ${ }^{11}$ é uma tradução para o italiano vernacular do Líber aggredatus in medicinis simplicibus, um tratado de plantas medicinais originário do século IX de autoria de Serapion, o jovem (Ibn Sarabi), e traduzido, no final do século XIV, por Jacopo Filippo.

Vale dizer que esses tratados estão historicamente ligados à medicina e à farmacologia, mas também à manutenção do poderio político - uma vez que a imitatio natura era uma fonte de legitimação do poder - e ao ocultismo e à alquimia. Dürer e Schongauer, por exemplo, são contemporâneos de Philippus Theophrastus Aureolus Bombastus von Hohenheim, também conhecido como Paracelsus (1493-1541), que preconizava que o estudo e imitação da natureza teria implicações alquímicas.

Apesar da diversidade e da natureza dos registros, é apenas no século XVII que os livros de ilustração científica botânica começam a ganhar a feição que conhecemos hoje. O surgimento de novas técnicas de observação (como o microscópio) e de novos métodos de representação (com a inauguração de técnicas de produção de pigmentos e avanços nas técnicas de impressão), a emergência do Empirismo no estudo da natureza e a possibilidade de uma nomeação científica universal proposta por Carlos Lineu, pai da moderna taxonomia, contribuem para esse novo fazer. De acordo Foucault (1966), ao abrir mão da operação da imaginação na linguagem, de seu movimento buliçoso e poroso, o naturalista do tempo de Lineu perde a vida. Foucault diz que até o fim do século XVIII, vida não existe. Apenas existem seres vivos formando uma ou várias classes na série de coisas catalogáveis no mundo. Em Les mots et les choses, Foucault diz que, nessa época, o privilégio da visão que recebe o endosso do pensamento de Lineu assegura que um cego possa perfeitamente ser um geômetra, mas jamais um naturalista.

A partir do século XVIII, com a empreita de desbravadores e desbravadores-cientistas, como James Cook, Alexander von Humboldt, Charles Darwin e Alfred Russel Wallace, um 
novo período é inaugurado no desenvolvimento da botânica e seus registros. Ajunte-se à abordagem de cunho empirista, legado do século anterior, a descoberta de novas espécies provindas de uma geografia ainda não completamente conhecida e as muitas dificuldades (de transporte, de observação, de catalogação, de preservação do material, de sistematização e de representação) dessa nova flora - o que precisou ser vencido com tenacidade e destreza científica, mas também com criatividade e sensibilidade, dando mostras de que a ciência é estéril sem uma boa dose de invenção.

Esse brevíssimo panorama serve para mostrar que os avanços do conhecimento botânico são produtos de descontinuidades históricas, de articulações e rearticulações entre campos diferentes do saber e de sucessivas traduções. Ressalte-se que essas traduções entre grego, latim, árabe e outras línguas vernaculares não implicam apenas em mudanças de códigos linguísticos, mas de contextos culturais, históricos e ideológicos. Ao contrário do que se pode imaginar, não é a degradação ou a perda dos manuscritos as principais causas das transformações e das rupturas, mas são os conhecimentos, as necessidades, os insumos de cada época, de cada povo, que rearticulam essas informações. Como afirma Walter Benjamin (1992), na Tese VI de seus escritos sobre o Conceito de História, não existe um acesso a um passado tal como de fato aconteceu. Toda recuperação histórica é uma tradução não do que "realmente foi", mas de uma lembrança que lampeja num instante de perigo. Também no discurso de Martius, embora seja o da catalogação atenta e criteriosa, o passado lampeja, alumia, abrindo clareiras misteriosas em sua escrita, gerando sombras e lusco-fuscos.

\section{O sonho, a sombra e o silêncio}

Mas quem? Ninguém? O homem é um sonho de sombra. (Píndaro)

Going up that river was like traveling back to the earliest beginnings of the world, when vegetation rioted on the earth and the big trees were kings. An empty stream, a great silence, an impenetrable forest. (Joseph Conrad, Heart of Darkness)

Entre os registros do Brasil feitos pelos viajantes, as imagens da obra Flora Brasiliensis apresentam bastante características singulares. Resultado de um olhar escrutinador e atento, que obedece a uma sintaxe rigorosa de elaboração, essas 
Figura 8

Flora Brasiliensis.

http://florabrasiliensis.cria.org.

br/opus

Figura 9

Exemplo de gravura da obra Historia naturalis palmarum: opus tripartitum. (Manicaria saccifera 2).c.1823. http://www. biodiversitylibrary.org/title/ b12036171. Public domain
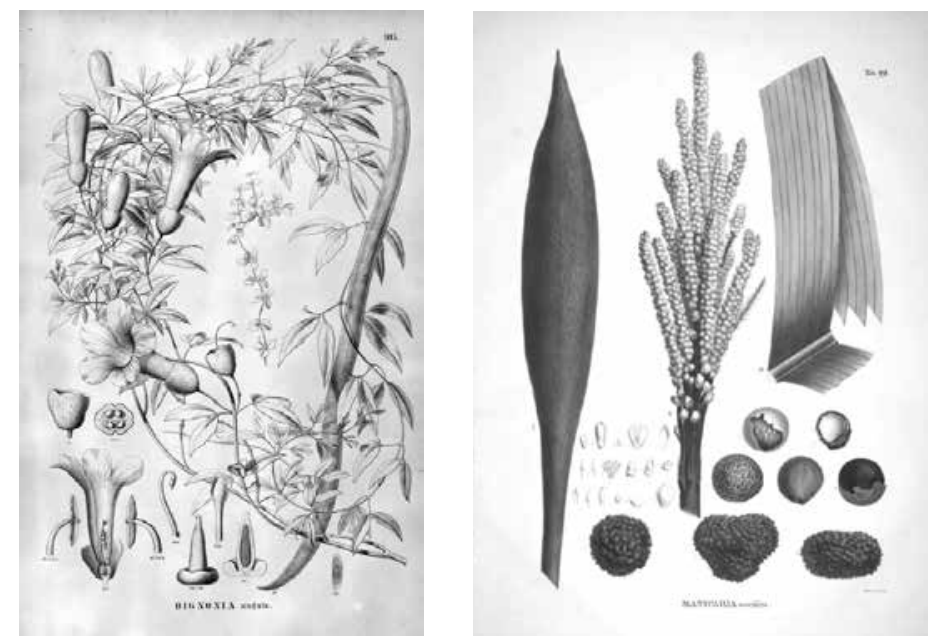

Figura 10

C. F. P. von Martius.

Flora Brasiliensis. Tabulae Physionomicae, n. IX

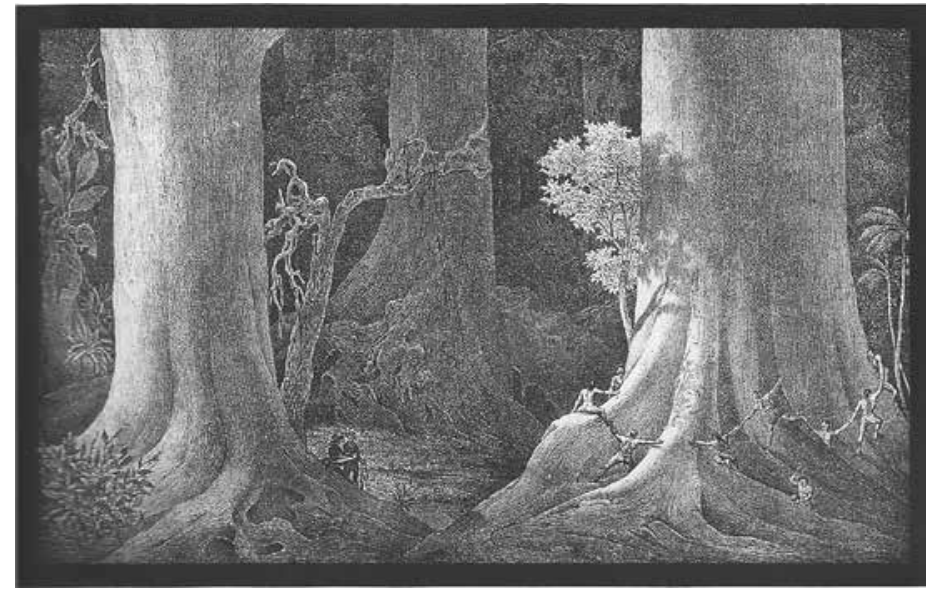

imagens tem finalidades mais científicas do que estéticas. Esta especificidade é corroborada pela presença da palavra que, embora em alguns momentos entre em franca disputa com o que se vê nas ilustrações, nos trabalhos de sistematização botânica, interfere na gramática do texto visual como aliada do olho, reforçando o pendor para o testemunhal e científico. Em obras Flora Brasiliensis (figura 8) e Historia naturalis palmarum (figura 9), diferentemente da botanical art produzida por artistas como Marianne North e Margaret Mee (para citar viajantes que, assim como Martius, se deslocam da Europa para os trópicos para registrar a flora brasileira), as descrições em latim e algumas vezes acompanhadas de numerais (como 
algarismos romanos e/ou números cardinais), aparecem na forma de legenda, contornando a imagem e fornecendo detalhes técnicos de uma planta ou de partes dela.

Como imagens, as Tabulae não são nem retratos de tipos humanos (como aparecem alguns exemplos em Reise in Brasilien) nem tampouco ilustrações botânicas que se detêm sobre a bainha, pecíolo ou folíolo de uma palmeira, mas paisagens (figura 10). Entretanto, na contramão da pintura e desenho de paisagem que se faz do Brasil no século XIX, as paisagens das Tabulae não se voltam nem para a arquitetura das cidades brasileiras nem para sua crônica de costumes, mas para o espaço não construído. Na paisagem, independente se a referência recai sobre uma realidade fantasiosa, onírica ou subjetiva ou se ela se alicerça sobre o real, o espaço, que por si é uma abstração, ganha contornos sígnicos. A paisagem é um signo do olhar que, acima de tudo, está interessado pela invenção do espaço. Ou seja, não é a paisagem que precisa do espaço físico, geográfico, para existir. Ao contrário, é a paisagem como construção simbólica que confere ao espaço a estruturalidade ou a gramaticalidade que faz com que ele se torne visível, pensável, comunicável. Talvez por isso a pintura, o desenho ou a fotografia de paisagem estejam, historicamente, tão próximos dos registros de viagem, quando o abandono do solo nativo e o encontro com outra geografia instiga a imaginação do observador, que sai de um estado distraído de percepção para uma postura ativa, vigilante e capaz não apenas de representar, mas de recriar o espaço sobre o qual se debruça.

A tradição de pintura de paisagem, que já existia no medievo como plano de fundo nos retábulos e nas miniaturas medievais e que é redimensionada por Dürer em suas andanças pela Europa, tem, no Brasil, a acolhida dos holandeses Frans Post e Albert Eckhout. O modelo paisagístico renascentista dos artistas viajantes, modelo que tem na paisagem italiana seu paradigma de visualidade, é reelaborado quando esses europeus se deparam com a topografia e natureza brasileiras. Com os viajantes cientistas do XIX, a tradição paisagística brasileira que tem origem com os artistas que acompanham Mauricio de Nassau é, mais uma vez, rearranjada.

As Tabulae, ainda tão pouco estudadas, são, portanto, a síntese desse equilíbrio e dessa tensão, na obra de Martius, entre o relato e a imagem, entre a palavra diária e a precisão científica, entre a poesia e a lâmina do microscópio, entre o vivido e a memória que o elaborou, entre o alvoroço da vida e 
a fixidez de sua representação, entre o projeto autoral e o seu desenrolar num plano coletivo. Nele, ora a palavra dá voz ao discurso apaixonado, romântico, místico e subjetivo e, em alguns momentos, excessivamente adocicado do escritor, ora ao botânico que coleta, mede, pesa, cataloga e classifica.

A dimensão da viagem incentivada por Humboldt e valorizada no Romantismo (CARPEAUX, 2012), preocupação que é um dos motores de Reise in Brasilien, nas Tabulae recai sobre o par palavra e imagem. Já na sua introdução, Martius diz que o intento de seu relato é inserir o leitor nas matas brasileiras - "os leitores serão levados a conhecer cada uma das plantas brasileiras como se estivessem lá". Não apenas os cientistas se deslocam, mas o leitor deve ser um transformado num viajante. Os relatos e as imagens da Tabulae devem conduzir o leitor, fazê-lo "percorrer com os olhos da alma" a natureza pródiga. As plantas devem ser experimentadas não como representações imagéticas ou descrições textuais de uma natureza inanimada que jaz na folha de papel, mas "como se estivessem vivas e exuberantes" (MARTIUS, 1996: 23). Mas, se na introdução das Tabulae ele se apega e persegue esse objetivo, no desenrolar do projeto lemos um Martius desapontado com a possibilidade das imagens e das palavras figurarem o mundo natural.

Embora, assim como os naturalistas de seu tempo, Martius recorra à imagem como forma de representação da natureza e apesar dos elogios que ele faz aos pintores cujas pranchas fazem parte do Tabulae Physiognomicae, é comum em seus escritos um tom de lamento pelo que julga ser uma impossibilidade da imagem em representar o real. A cor do céu, por exemplo, é impossível de ser copiada "por mais que seja a habilidade de um pintor", tamanha a "delicadeza e esplendor daquele diáfano céu tropical” (Tabula VII). Já na Tabula de número XIII, Martius diz que nenhuma pintura é capaz de reproduzir a cor das pétalas da orquídea Cattleya guttata (representada como um pequeno detalhe na prancha).

Assim como Martius, outros naturalistas de seu tempo mantem uma reação oscilante com as artes plásticas. Segundo Diana Donald e Jane Munro, na obra The endless forms Charles Darwin, Natural Sciences and the Visual Arts, quando Darwin viu pela primeira vez as florestas equatoriais da América do Sul a bordo do Beagle, sua reação foi compará-las às paisagens do Brasil feitas por Comte de Clarac e Rugendas. Em carta à sua irmã, em 1832, ele afirma seu "intense delight" 
em ver com seus próprios olhos o que já havia experimentado nas obras desses artistas. Contudo, para Darwin, a arte nunca poderia se equiparar à natureza em sua superabundância de vitalidade e diversidade (DONALD e MUNRO, 2009). Também Humboldt, que valorizava a sensibilidade dos artistas para a apreensão dos trópicos, é um apreciador do trabalho de Rugendas, que para ele era o criador da arte da representação da fisionomia da natureza brasileira, tendo incluído um conjunto de desenhos seus na reedição de seu Géographie des plantes. Além de Rugendas, Humboldt considera Frans Post o iniciador da ligação entre arte e ciência e reconhece a importância de Eckhout numa época em que esse artista não havia recebido a valorização merecida (BELLUZZO, 1994).

O desencantamento com a representação, no Romantismo, entretanto, é paradoxal. O desassossego na recomposição do vivido não silencia o autor. Ao contrário, o impele a uma narração escoltada pela falta, pelo erro, como uma sombra ameaçadora capaz de a qualquer momento emudecê-la. O dizer ordenado (a história natural a partir de Lineu como domínio da ordem, como discute Foucault) do Flora Brasiliensis com sua natureza exposta, esclarecida e catalogada entra em tensão com um dizer poético e falho que abre clareiras de silêncio no meio da massa verde, muitas vezes descrita como um lugar agradável, repousante e cheio de vida.

Mas a visão de uma morte que está oculta ("É como se a mão hábil de um artista distribuísse tão sabiamente a vida que chega a ocultar a morte", diz Martius na Tabula VI) se despedaça quando a natureza brasileira dá provas de sua inexatidão. A fartura maternal ("a imensa quantidade de coisas, a inesgotável fecundidade da vegetação"; "a enorme força de gerar que possui esta terra é submetida ao império da beleza e que tudo é nela tocado pelo sopro de uma doce harmonia", vide Tabula $V I I$ ), a amável e ordenada natureza (ele diz que de uma natureza que "afeta, acalma e diverte o ânimo benigno" de quem a contempla e que sua vegetação, além de "feraz e majestosa, é agradavelmente constituída e ordenada", Tabula IV) tem seu avesso na imensidão madrasta: o descomunal não é mais fonte incessante de fortuna e felicidade, mas de angústia e desterro.

Na obra de Martius, é comum ouvirmos que a beleza do Brasil é opulenta porque contraditória. Abriga pares de opostos: "isto tudo não poderia produzir aquela terra belíssima, ou aquele elísio humano como podemos chamar, se por todo 
lado as coisas se ordenassem do mesmo modo, obedecendo a um único movimento" (Tabula VII). Quando se refere à floresta primitiva de Jacareí, diz que por mais que a visão da floresta o tenha comovido, ele não pode negar que, percorrendo-a, ela não lhe tenha parecido "rude, triste e inóspita" assim como lhe pareceram ameaçadores e ferozes os índios daquela região. A desolação estende-se aos primeiros habitantes daquele lugar, diz Martius referindo-se ao que restou dos caryôs e guarûs que sobreviveram à varíola e às armas de fogo dos colonos: "nenhum deles deixa vestígio e os ossos apodrecidos daqueles índios são cobertos pelas sombras indevassáveis da floresta que confirma o quanto a força vital das plantas supera a fragilidade dos homens". E alude a Píndaro, citando-o: "Mas quem? Ninguém? O homem é um sonho de sombra"(Tabula VIII). Na Tabula VI, lê-se: "Porventura não é ela mesma (a floresta) um cemitério, onde a vida de cada um, depois de ter florescido por um instante, recebe o abraço comum da morte?".

O simbolismo da sombra é recorrente nos seus escritos. Martius refere-se às sombras da floresta abrigando mortes e também ao homem como sombra (sonho de sombra) devido à sua exiguidade - que está ligada ao perecimento, mas também à sua irrelevância quando comparado ao permanente poder de renovação das matas. Em uma determinada passagem, a sombra alude ao Hades, deus dos mortos e do mundo inferior e designação do lugar para onde são levados os seres que passarão a habitar trevas mais densas. Quando se refere aos índios sobreviventes, Martius diz que dispersos e deformados eles se acabam "à maneira dos habitantes das sombras profundas" (Tabula XVIII). Além de insignificante e breve, o homem tem suas certezas abatidas diante do desusado. No meio da floresta da Serra dos Órgãos, Martius diz que "em vão o europeu procura em torno, nesse labirinto verde, formas conhecidas ou plantas nas quais o olhar de um certo modo possa repousar". E acrescenta: "tudo lhe parece novidade" (Tabula VI).

Além da grandiosidade da natureza, que faz com que o humano pareça mínimo, esmagado por tudo o que o cerca, a dimensão temporal das árvores em relação ao tempo de duração da vida humana também reforça a sensação de pequenez e impotência. A ideia de árvores como entidades imperturbáveis, alheias à finitude dos homens aparece vários momentos na obra. Lê-se na Tabula IX: "Todos aqueles povos bárbaros americanos que não chegaram a se tornar conhecidos, surgiram e desapareceram sem deixar qualquer vestígio, mas estas árvores continuam vivendo a sucessão de seus dias". 
Perplexidade diante do novo, sentimento de desolação, morte, desacomodação, estranhamento frente ao que deveria ser conhecido e familiar e a grandiosidade violenta da natureza esmagando o humano são características do que Immanuel Kant, no século XVIII, chamará de sublime e que está relacionado, em sua obra, ao julgamento estético provocado pelo encontro com a natureza. Na obra de Martius, notadamente três aspectos confirmam esse pendor: a morte, que estava sempre presente no seu caminho como mostra a leitura de Reise in Brasilien, mas sobretudo o sentimento de morte que não necessariamente está no plano fisiológico, mas que é resultado da experiência com o irremediável, o trágico; a desproporção do homem em relação à magnitude da natureza (o que Kant chamará de sublime matemático) e a atemporalidade da natureza em comparação à finitude de cada homem.

Embora os historiadores ressaltem a recorrência da representação que toma a via do pitoresco na retratação do Brasil feita pelos pintores do século XIX, é importante perceber que essa representação não é absoluta, como nos revela a leitura dos relatos de viagem de Martius e de sua Tabulae Physiognomicae. Como afirmou Alfred Russel Wallace em seu Narrative of Travels on the Amazon and Rio Negro ${ }^{13}$,

...drawing travellers, who, by only describing the beautiful, the picturesque and the magnificent, would almost lead a person to believe that nothing of different character could exist under a tropical sun.

Em termos de imagem, como dissemos inicialmente, as imagens da Tabulae são paisagens. Avançando no sentido das investigações da paisagem natural, que dá norte à reflexão estética ligada à paisagem no século XVIII e que baliza os modelos paisagísticos dos pintores e desenhistas de paisagem que chegam ao Brasil a partir do século XIX, encontraremos atitudes distintas em relação à natureza. Segundo Giulio Carlo Argan (2010), na raiz do Romantismo há duas formas de representação e interpretação da paisagem natural. Ligado ao sentimento do trágico, à sensação de desolamento e solidão diante do grandiosamente assombroso e terrível, o sublime, na acepção de I. Kant (Crítica da Faculdade do Juízo) e de E. Burke (A Philosophical Enquiry into the Origin of Our Ideas of the Sublime and Beautiful) entra para o vocabulário artístico alguns séculos depois do sentido que lhe atribui Longino (Peri Hupsous/Hypsous) ${ }^{14}$, agora se opondo ao belo e se filiando ao temor reverencial diante da natureza. 
O sublime kantiano está além do belo como harmonia e proporção. Para a antiguidade clássica, a noção de infinitude está ligada à de imperfeição, falsidade, irracionalidade, feiura, pois se enreda com a desproporção. Eugénio Trías, entretanto, ressalta que essa pressuposição é questionada inicialmente pela teologia patrística, mas perdura até o século XVIII, ainda que, antes de Kant, São Basílio, São Gregório de Nisa e Santo Agostinho já tenham falado do limite em termos positivos criando imagens como o pélago profundo, a fogueira ardente presenciada por Moisés, a extensão do oceano e dos desertos que inclinam o espírito para uma aceitação da noção de finitude (a divindade, plenipotenciária, é infinita).

Nas artes plásticas, o sublime se reconhece em expressões que, embora muito diferentes, têm pontos comuns. As cores são desbotadas e os gestos excessivos. O inóspito é retratado, são paisagens selvagens, penhascos e árvores retorcidas que muito se afastam da natureza domesticada dos jardins do pitoresco. A natureza selvagem e inclemente de Salvator Rosa, a produção fantasiosa e alucinada de Blake, a força devastadora do fogo, da água, dos ventos retratada por William Turner e a solidão da pequenez das personagens de Caspar David Friedrich são exemplos da irracionalidade que dão contornos ao sublime como categoria estética.

Como dissemos, o primeiro volume da Flora Brasiliensis é formado pelas Tabulae Physiognomicae, num total de 59 . As 42 primeiras vêm acompanhadas de texto, daí em diante são só gravuras. Embora seja comum encontrarmos traços de uma escritura que se debruça sobre o sublime, as imagens que acompanham o relato não têm a mesma preocupação.

Contemporânea do sublime, a estética do pitoresco ressalta imperfeições em cenas repletas de detalhes curiosos, próximos de uma natureza que nada tem de hostil, mas que é agradável e generosa. A primeira citação está em Vasari que, no século XVI, usa o termo pitoresco para indicar um tipo de desenho que tende a obter efeitos pictóricos. Embora o termo tenha raízes na Itália do século XVII (diz-se pitoresco do modo de pintar alla brava, ou seja, de impulso, desembaraçadamente), é na Inglaterra do século XVIII que o conceito de pitoresco como expressão estética será elaborado com maior sistematicidade. Artistas e teóricos, como William Gilpin (1724-1804), Uvedale Price (1747-1829), Richard Payne Knight (1750-1824) e Alexander Cozenz (1717-1786), refletem sobre uma poética do pitoresco em oposição ao sublime. O conceito se liga à pai- 
sagem domesticada, cuidadosamente elaborada dos jardins ingleses ${ }^{15}$, onde a natureza é submissa, ainda que preserve certa espontaneidade. Se o sublime se dirige ao infinito, ao trágico e ao incontido, o pitoresco reforça o mutável e o relativo.

Visitando Kant, o filósofo Eugénio Trías associa o sublime à temática que persegue por praticamente quase toda a sua obra, sobretudo a partir dos anos 1980: o limite. Para Wittgenstein, os limites da linguagem são os limites do mundo. Esse axioma, que conjuga linguagem, lógica e mundo, herda de Kant um conceito de fronteira que marca a capacidade intelectual humana. Ou seja, a modernidade trata de forma negativa o limite. É um saber convencional, dirá Eugénio Trías, mero sinal do nec plus ultra (TRÍAS, 1991), além do qual a nossa compreensão, no dizer de Hegel e Kant; ou de nossa fala, como propõe Wittgenstein, não são capazes de ultrapassar. Trías formula seu conceito de limite a partir dessa inquietação e parte da experiência concreta do império romano para conceber o limite como uma teoria ontológica de características estética e metafísica. Os limitanei eram habitantes do limes que cultivavam a terra ea defendiam com armas. Além da circunscrição do limes estavam os bárbaros. Deste modo, o conceito de limite está relacionado ao de cultura uma vez que quer dizer do cultivo (colere) territorial e espiritual (culto aos mortos).

Fronteiriça e contraditória é a visão de Martius. Se em Reise in Brasilien, há momentos em que a natureza é rigorosamente descrita e corresponde à ideia de um paraíso na terra, em outros encontramos registros de uma experiência terrível e trágica, que evoca o horror diante do descomunal - o que Martius chega mesmo a comparar ao inferno dantesco:

Escura como o inferno de Dante fechava-se a mata, e cada vez mais estreita e mais íngreme, a vereda nos levou por labirínticos meandros, a profundos abismos, por onde correm águas tumultuosas de riachos, e, ora aqui, ora ali, jazem blocos de rocha solta. Ao horror, que esta solidão agreste infundia na alma, acrescentava-se ainda a aflitiva perspectiva de um ataque de animais ferozes ou de índios inimigos que a nossa imaginação figurava em pavorosos quadros, com os mais lúgubres pressentimentos (MARTIUS e SPIX, 1981: 220, livro 1).

Na Tabula XXI, quando conta de uma queimada provocada por fogos num verão seco na região ocidental da província de Minas Gerais, a referência não recai mais sobre Dante mas sobre 
o Êxodo bíblico (vide Ex. 13, 21). Diz Martius: "Caminhando por esses desertos que se inflamam vemos, frequentemente, nuvens que os ventos reúnem da cinza e da fumaça e avançam pelos campos, horríveis de ver; o mesmo espetáculo que as colunas de nuvens ofereceram aos israelitas que marchavam pelo deserto".

\section{Novamente o vazio o engole}

Pois o belo não é senão o começo do terrível, que só a custo podemos suportar/ E o admiramos tanto porque ele tranquilamente desdenha nos destruir. (Rainer Maria Rilke. Duineser Elegien)

Filósofo do limite, Trías é também o filósofo da sombra e do sinistro. Apoiando-se em Rilke ("o belo é o começo do terrível que ainda é possível suportar") e em Schelling, para quem o sinistro/estranho (Das Unheimliche) é aquilo que, devendo permanecer oculto, se revelou, Trías diz que o sinistro é a condição e também o limite do belo. Trías quer contemplar, em suas próprias palavras, o avesso do tapete, perceber a face oculta, ominosa e sombria que normalmente se deixa fora da representação. $\mathrm{O}$ sinistro deve estar presente como supressão, como ausência, como revelação do que deve permanecer oculto sob pena de produzir uma imediata ruptura do belo.

O sublime kantiano configura-se como um temor reverencial e doloroso. Diante do grandioso, do ilimitado da natureza, o ânimo abandona o sujeito, que se sente esvaziado e diminuído. Se a consciência empapada de sentimentos de angústia e pavor reconhece sua insignificância, de onde viria, então, o prazer do sujeito que se vê ameaçado pela proximidade com a violência destrutiva do objeto? O objeto é pretexto e ocasião para que o sujeito, atingido pela majestade do lugar, exponha faculdades que são suas e não do objeto, diz Eugenio Trías (1991). Esse temor, ao mesmo tempo em que afasta o sujeito, também o atrai.

Atraído e instigado pela mata, Martius dedicará os próximos anos de sua vida à natureza brasileira. Quando, após três anos de permanência no Brasil, Martius retorna à Alemanha em 1820, aos 26 anos de idade, compilará o material coletado em criteriosos tratados botânicos, mas também se encarregará da reconstituição de suas memórias. Nelas, a mata ocupa o lugar do desmesurado, da imensidão sem vestígios, que enche 
o coração dos homens do "sagrado temor da presença divina" (Tabula IX). Na mata brasileira ("ai do cansado viajante que, a pé e sozinho, é levado a erro nesta imensidão de arbustos, onde não há vestígios de cultura humana; tudo é indício de uma natureza primitiva", Tabula XXIII), encontramos Goethe: "Mas porém quem é ele? Entre os arbustos perde-se seu rastro, atrás dele fecham-se os arbustos as hastes da grama erguem-se novamente o vazio o engole!" ("Aber abseits, wer ist's? In's Gebusch verliert sich sein Pfad, Hinter ihm schlagen, Die Strauch zusammen, Das Gras stcht wieder auf, Die Oede verschlingt ihn”). Em seus escritos, a literatura se confunde com a precisão científica, inventando experiências e recriando memórias.

O cansaço, as febres, companhia permanente da morte, a presença dos mosquitos, o desconforto das noites ao relento e da precariedade dos transportes são vivências que o pesquisador de gabinete não experimentaria em sua jornada, mas que cientistas-viajantes tiveram que lidar com elas e acabaram por imprimir essas marcas em suas descobertas. Aprendizados com o vazio que engole, com o imprevisível, com o que até então não havia ainda sido rotulado, com o desmedido que leva o pesquisador a erro, instigando-o à desconfiança de que nem tudo cabe no verbo, de que há sensações que não se ajustam ao dizer claro da taxonomia de Lineu. Mas também na imagem repousa a sombra da dúvida. Martius queixa-se da imprecisão dos ícones, antevendo a característica fundamental da imagem, que é sua capacidade de flutuação, de desprendimento das formas, de volatilidade e readequação, sem a qual seria impossível se falar de imaginário.

Esse desnorteamento tem implicações científicas e estéticas e borra os limites entre imparcialidade e subjetividade, entre memória e fantasia, entre ciência e arte. Martius, leitor de Goethe e de Humboldt e adepto da Naturphilosophie de Schelling, se sente ameaçado e angustiado diante da natureza que ele julgava poder analisar. Em seu legado, natureza e cultura se entrelaçam num texto visual e literário complexo, que deu grande contribuição para a botânica de seu tempo, mas que a ultrapassa. Gestado entre falhas, clareiras, não ditos, a obra de Martius propõe questões que, embora assentadas sobre um olhar e uma realidade própria de um tempo, transbordam.

Como produzir, cientificamente, um saber útil à vida? Um conhecimento que possa propor respostas às urgentíssimas questões ecológicas? E mais: de que ciência estamos 
falando? É preciso ter em conta que o conhecimento produzido sobre a natureza não apenas a reflete, mas também a modifica, assim como a natureza também provoca o seu intérprete. Ou seja, tão importantes para a representação sígnica da natureza brasileira quanto os biólogos, farmacêuticos e botânicos que faziam parte das expedições do século XIX, são os pintores, os desenhistas e os escritores. Indistintamente, as produções de cientistas ou de artistas apresentam "verdades" que serão sempre provisórias e (novamente) indistintamente seja o conhecimento produzido pela arte ou o produzido pela ciência será sempre fruto de sistemas de crenças. O naturalista e a natureza como seu objeto de pesquisa são inteligências (ou minds, para usar um termo caro a Peirce) que se contaminam. Na obra de Martius o que percebemos é que se por um lado existe um cientista atento aos paradigmas de seu tempo, por outro há um indivíduo que se espanta, que se afrouxa, que se alarga e que escreve e desenha poeticamente sobre essa vertigem. Os signos concebidos por essa interação nunca serão nem o que o mundo natural é nem o que se pensa sobre ele, mas resultados de processos interpretativos que não cessam por que nunca se completam. Dito de outro modo: no signo, há sempre algo que escapa.

NOTAS

1. A correspondência digitalizada entre Martius e Goethe pode ser acessada aqui: http://dfg-viewer.de/show/?set[mets]=http\%3A//digital.ub.uni-duesseldorf.de\%2Foai\%2F\%3Fverb\%3DGetRecord\%26metadataPrefix\%3Dmets \%26identifier\%3 05276571.

2. Humboldt é expulso do Brasil na fronteira com a Venezuela. Sua expedição, que percorreu quase 10 mil quilômetros a pé, a cavalo ou em canoas, passa por territórios que atualmente correspondem aos domínios da Venezuela, Colômbia, Equador, Peru, Cuba e México.

3. O conteúdo da obra Flora Brasiliensis pode ser consultado na página http:// florabrasiliensis.cria.org.br, do Cria (Centro de Referência em Informação Ambiental), associação civil e sem fins lucrativos, que atua no sentido de disseminar o conhecimento científico e tecnológico. O Cria desenvolveu um sistema de informação on-line sobre a flora brasileira com imagens digitalizadas pelo Jardim Botânico de Missouri. Os trabalhos referentes à atualização dos nomes pelos pesquisadores ficou a cargo do Departamento de Botânica do Instituto de Biologia da Universidade Estadual de Campinas, a Unicamp.

4. Além de Flora Brasiliensis, Martius escreveu, em parceria com J. B. Von Spix (embora os volumes 2 e 3 tenham sido publicados após a morte de Spix, Martius faz questão de preservar seu nome como coautor dos três volumes), Viagem pelo Brasil (Reise in Brasilien), publicado em três volumes em 1823/1828/1831 contando de sua expedição pelos estados brasileiros do Rio de Janeiro, São Paulo, Minas Gerais, Bahia, Pernambuco, Piauí, Maranhão e Amazonas, num total 
de mais de 10 mil quilômetros, e que seria a base para o desenvolvimento das obras posteriores; Nova Genera et species plantarum, também em 3 volumes (o primeiro publicado em 1823 e o último em 1832) com 300 litografias, que seria a descrição do acervo botânico da expedição, conta com 70 gểneros novos e 400 espécies botânicas coletadas no Brasil feitos a partir de detalhes analíticos (desenhos que seguem a convenção de Lineu) reproduzidos por Martius ao natural; entre 1828 e 1834 Martius publicou um tratado sobre plantas criptogâmicas chamado Icones Plantarum Cryptogamicarum; Historia naturalis palmarum (1823 a 1853), obra pela qual Martius tornou-se conhecido pela comunidade científica como "pai das palmeiras", é composto por 245 pranchas com palmeiras de diversas partes do mundo; e Herbarium Florae Brasiliensis (publicado entre 1837-1841), obra que dá origem ao Flora Brasiliensis, faz uma retrospectiva de todos os naturalistas que visitaram o Brasil e coletaram material desde o descobrimento (Martius calculava em torno de 15.000 o número de exemplares coletados e dispersos em diversos herbários europeus). Aventurando-se pela ficção, Martius escreveu Frey Apolônio - um romance do Brasil.

5. Quando Martius morre, em 13 de dezembro de 1868, já haviam sido publicados 46 fascículos da obra, com 10 mil espécies descritas e 1.100 estampas ilustrativas.

6. O título completo é Tabulae physiognomicae. Brasiliae regiones iconibus expressas descripsit deque vegetation illius terrae uberius, que teria a tradução aproximada de Estampas fisionômicas. As regiões do brasil descritas e representadas por imagens e a vegetação dessa terra amplamente exposta.

7. Sobre esse autor, Martius diz apenas que a Tabula de número XXII é de autoria do: "amicíssimo Dr. Estevão, médico escolhido da viúva Amália, o qual viveu algum tempo naquela região da província de $M G$ ”.

8. Sobre a Tabula XL, Martius diz que foi feita "a partir de um esboço que fiz aí mesmo, que a mão habilidosa do litógrafo Aug(ust) Brandmueller conseguiu representá-la". Também a Tabula XLIV é elaborada por Brandmueller, mas dessa vez a partir de uma obra de Johann Steinmann (Plantação de Café, c. 1836; água-tinta, $110 \times 165 \mathrm{~mm}$, atualmente pertencente à Coleção João Moreira Garcez). Sobre a autoria da Tabula XLIV ver a página do Cria com a indicação (http://florabrasiliensis.cria.org.br/info?Vo1P1Noo44).

9. Os biógrafos não conseguem precisar o ano de nascimento e morte de Dioscorides, mas se pode dizer que ele nasceu no primeiro quarto do primeiro século da era cristã.

10. Figura 6 disponível em: Albertina Museum online: http://gallery.albertina.at/eMuseum/code/emuseum.asp? style=browse \&currentrecord=1\&page= search\&profile=objectsde\&searchdesc $=$ Schnellsuche $\%$ oenthält $\% 20$ Rasen stück\&searchstring=quicksearch/,/enthält/,/Rasenstück/,/false/,/false\&ne wvalues $=1 \&$ newstyle=single\&newcurrentrecord $=1$. Google cultural institute: http://www.google.com/culturalinstitute/asset-viewer/the-large-piece-of-turf-1503/NgELdACk3I8Jkg. Public domain.

11. O arquivo digitalizado contendo o Carrara Herbal, de autoria de Serapion the Yonger, pode ser acessada no Catalogues of Illuminated manuscripts da British Library: http://www.bl.uk/catalogues/illuminatedmanuscripts/ record.asp $\mathrm{MSID}=8320 \&$ CollID $=28 \& N S t a r t=2020$.

12. Figura 7 disponível em: http://www.bl.uk/catalogues/illuminatedmanuscripts/record.asp?MSID=8320\&CollID=28\&NStart=2020.

13. A versão digitalizada da edição de 1889 está disponível no site https:// archive.org/details/narrativeoftraveoowall. E foi digitalizada pelo BHL (The Biodiversity Heritage Library. Acesso em: 02 de fevereiro de 2014.

14. A filiação do tratado de Longino à tradição de estudos do sublime é questionada por alguns filósofos. Além disso, a autoria do Peri Hopsous, 
cujo Codex Parisiensis 2036, do século X, é o melhor e mais antigo fragmento (ainda que um terço desse esteja corrompido) é discutível. Além de Longino (213 - 237 A.D), discípulo de Amonio, o autor também pode ser Cassius Longinus, Dionysius Longinus ou Dionisyus de Halicarnassus.

15. Uma das consequências do pitoresco é a jardinagem. $O$ jardim inglês é uma forma de impor à natureza o que a mente humana pensa sobre ela e de ensinála como ela deveria se comportar. O termo tem raízes no classicismo barroco, em especial na pintura de paisagem de Claude Lorrain, Nicolas Poussain e Salvator Rosa. Pitoresco é "o que já foi dito ou o que pode ser dito mediante a pintura", diz Argan (2010: 113). Os significados míticos alusivos à Arcádia e a natureza em oposição à paisagem urbana são as bases nas quais se alicerça a poética do pitoresco na Inglaterra. Do ponto de vista sociológico, quando a grande propriedade de terra vai se desmembrando, os pequenos burgueses ingleses tornam-se proprietários de lotes onde construirão suas casas de veraneio. A esses pequenos idílios de evasão se opõem à paisagem urbana que é tida como uniforme, invariável, artificial e exageradamente prática, lugar onde o homem, com a mente excessivamente atenta aos estímulos do ambiente, não será jamais capaz de contemplar o mistério do mundo.

\section{Referências}

ASSIS JUNIOR, Heitor de. As pranchas fisionômicas e seus modelos. Disponível em: <http://florabrasiliensis.cria.org.br/ info?plates>. Acesso em: o5 de fevereiro de 2014.

ASSIS JUNIOR, Heitor de. Relações de von Martius com imagens naturalísticas e artísticas do século XIX. 2004. 195 f. Dissertação (Mestrado) - Cursode Programa de Pós-graduaçãoem História, Unicamp, Campinas, 2004. Disponível em: <http://www.bibliotecadigital.unicamp.br/document/?code=vtlsooo316130 $>$. Acesso em: 05 de fevereiro de 2014.

BELLUZZO, Ana Maria de Moraes. O Brasil dos viajantes. São Paulo: Metalivros, 1994. Vols. 1, 2 e 3.

BENJAMIN, Walter. Teses sobre o Conceito de História. In: Sobre Arte, Técnica, Linguagem e Política. (Trad. Maria Luz Moita, Maria Amélia Cruz e Manuel Alberto; Prefácio de Theodor Adorno); Lisboa: Antropos, 1992.

BRIENEN, Rebecca Parker. Albert Eckhout (Obra Completa) - visões do paraíso selvagem. Rio de Janeiro: Capivara, 2010. BURKE, Edmund. A Philosophical Enquiry into the Origin of Our Ideas of the Sublime and Beautiful. Oxford: Oxford UK, 1998.

CAMPOS, Haroldo. Metalinguagem E outras metas. São Paulo, Perspectiva: 2006.

CARPEAUX, Otto Maria. O Romantismo por Carpeaux - das origens do Romantismo ao fim do movimento: o evasionismo, o byronismo, os radicais e utopistas. São Paulo: Leya, 2012. (História da Literatura occidental, n. 6) 
CORRÊA DO LAGO, Pedro (org.). Brasiliana Itaú. Rio de Janeiro: Capivara, 2009.

CORRÊA DO LAGO, Pedro e Bia. Frans Post $\{1612-1680\}$ Obra Completa (2a edição). Rio de Janeiro: Capivara, 2009.

DICIONÁRIO DE ESTÉTICA (Direção de Gianni Carchia e Paolo D'Angelo). Lisboa: Ed. 70, 2009.

DONALD, Diana e MUNRO, Jane. The endless forms - Charles Darwin, Natural Sciences and the Visual Arts. New Haven, Conn; London, Yale University Press, 2009.

FOUCAULT, Michel. Les mots et les choses - une archéologie des sciences humaines. Paris: Gallimard, 1996.

GOMBRICH, E.M. The Story of Art. London: Phaidon, 1996.

HAUSER, A. História Social da Arte e da Literatura. São Paulo: Martins Fontes, 1995.

HOLANDA, Sérgio Buarque. Visão do Paraíso: os motivos edênicos no descobrimento e colonização do Brasil. São Paulo: Brasiliense; Publifolha, 2000.

HUMBOLDT, Alexander von and BONPLAND, Aimé. Personal narrative. Abridged and translated with an introduction by Jason Wilson and a historical introdution by Malcomm Nicolson. London: Penguin, 1995.

HUMBOLDT, Alexander von. Cosmos: a sketch of a physical description of the universe. Baltimore;London: Johns Hopkins Press, 1997.

Quadros da natureza. São Paulo: W.M. Jackson Inc.2, 1950. Vols 1 and 2.(Clássicos Jackson).

JAKOBSON, Roman. Liguística e Comunicação. São Paulo: Cultrix, 1975.

KANT, Immanuel. Crítica da Faculdade do Juízo. São Paulo: Forense Universitária, 2012.

KURY, L. Viajantes-naturalistas no Brasil oitocentista: experiência, relato e imagem. História, Ciencias, Saúde Manguinhos, vol. VIII (suplemento), 863-80, 2001. Also may be available on: http://www.scielo.br/pdf/hcsm/v8so/ao4vo8so.pdf

KYLE, Sarah Rozalja. The Carrara Herbal in Context: Imitation, Exemplarity, and Invention in Late Fourteenth-Century Padua. 2010. 130 f. Dissertação (Mestrado) - Curso de Art History, Departamento de Art History, Laney Graduate School - Emory University, Atlanta - Us, 2010. Disponível em: <https://etd.library.emory.edu/view/record/pid/ emory:7v5f8>. Acesso em: 20 de janeiro de 2014.

LISBOA, Karen Macknow. A nova Atlântida de Spix e Martius: 
natureza e civilização na Viagem pelo Brasil (1817-1820). São Paulo: Hucitec, 1997.

LOTMAN, Iuri. Universe of the mind - a semiotic theory of culture. Bloomington and Indianapolis: Indiana University Press, 2000.

MARTIUS, Carl Friedrich Philipp von e SPIX, Johann Baptiste von. Viagem pelo Brasil (1817-1820). Belo Horizonte: Ed. Itatiaia; São Paulo, Ed. Da Universidade de São Paulo, 1981. 3 vols. . A viagem de von Martius: Flora brasiliensis, Volume 1. Rio de Janeiro: Editora Index, 1996.

. Flora Brasiliensis: a obra. Disponível em: <http:// florabrasiliensis.cria.org.br/opus>. Acesso em: 6 set. 2012.

MARTIUS, Carl Friedrich Philipp von. Flora Brasiliensis: seu enumeratio plantarum. From Biodiversity Library. Disponível em: <http://www.biodiversitylibrary.org/item/27737\#page/6/ mode/1up $>$. Acesso em: 08 de setembro de 2012.

. Flora brasiliensis: seu enumaratio plantarum in Brasilia tam sua sponte quam accedente cultura provenientium/quas in itinere auspiciis Maxmiliani Josephi I. Bavariae regis annis 1817-1820 peracto collegit, partim descripsit; alias a Maximiliano seren. Principe Widensi, sellovio aliisque advectas additit; communibus amicorum propriisque studiis secundum methodum naturalem dispositas et illustratas edidit C. F. Ph de Martius. Monachii et Lipsiae: apud R. Oldenbourg in comm. 1840-19o6.

. Historia naturalis palmarum: opus tripartium, cuis volumen primum palmas singulatim tractat; volumen secundum Brasiliae palmas singulatim descriptione et icone illustrat; columen tertium ordinis, familiarum, generum characteres recensetnspecies selectas describit et figuris adumbrat adiecta omnium synopsi. Accedunt tabulas CCXLV. Monachii impensis acutores, Lipsiae : Apud Frid. Fleischer, 1823-50. . Icones plantarum cryptogamicarum quas in itinere annis MDCCXVII-MDCCCXX per Brasiliam jussu et auspiciis Maximiliana Josephi I / Bavariae regis augustissimi instituto collegit et descripsit Carol. Frideric. Philipp. De Martius. Monachii: Impensis Auctoris, 1828-1834.

The book of palms/Das buch der palmen/Le livre des palmiers. Text by/text von/texte de H. Walter Lack. Köln, Taschen, 2009.

O'MALLEY, Therese and Amy R. W. Meyers (Editors). The art of Natural History: illustrated treatises and botanical pain- 
tings 1400-1850. New Haven and London; Yale University Press; Center for Advanced Studies in the Visual Arts and the Publishing Office, National Gallery Art, Washington, 2010. (Studies in the History of Art, 69).

PEDRAS, Lúcia Ricotta. A paisagem em Alexander von Humboldt: o modo descritivo dos quadros da natureza. Revista Usp, São Paulo, v. o8, n. 46, p.97-114, o1 jun. 200o. Disponível em: <http://www.usp.br/revistausp/46/o8-luciaricotta. pdf $>$. Acesso em: og de setembro de 2012.

PEIRCE, Charles Sanders. Collected Papers. Disponível em http://ssmith.no-ip.org/ebooks/_staging/pdf/Charles\%20 Pierce\%20-\%2oCollected\%2oPapers\%2oVol.\%201.pdf. Acesso em: 03 de Janeiro de 2014.

. The published works of Charles Sanders. Disponível em: <http://www.pragmaticism.net/works>. Acesso em: 3 jan. 2014.

PLAZA, Julio. Tradução Intersemiótica. São Paulo: Ed. Perspectiva, 2003.

REVISTA USP: Dossiê O Brasil dos viajantes. São Paulo: Universidade de São Paulo, n. 30. June/July/August 2006. Disponível em: http://www.usp.br/revistausp/30/EDITORIAL-30. htm. Acesso em: o1 de setembro de 2012.

RUGENDAS, Johann Moritz. Viagem pitoresca através do Brasil. Belo Horizonte: Itatiaia, 1998.

SMITH, Pamela. Artisanal knowledge and the Representation of Nature in Sixteenth-Century. In: O'MALLEY, Therese and Amy R. W. Meyers (Editors). The art of Natural History: illustrated treatises and botanical paintings 1400-1850. New Haven and London; Yale University Press; Center for Advanced Studies in the Visual Arts and the Publishing Office, National Gallery Art, Washington, 2010. (Studies in the History of Art, 69). P. 15-31.

TOUWAIDE, Alain. Botany and humanism in the Renaissance: background, interaction, contraditions. In: O'MALLEY, Therese and Amy R. W. Meyers (Editors). The art of Natural History: illustrated treatises and botanical paintings 14001850. New Haven and London; Yale University Press; Center for Advanced Studies in the Visual Arts and the Publishing Office, National Gallery Art, Washington, 2010. (Studies in the History of Art, 69). P. 33-61.

TRÍAS, Eugenio. Lo bello y lo siniestro. Barcelona: Random House Mondadori, 2006. 
TRÍAS, Eugenio. Los límites del mundo. Barcelona: Ed. Destino, 1991.

WALLACE, Alfred Russel. A Narrative of Travels on the Amazon and Rio Negro: with an account of the native tribes, and observations on the climate, geology and natural history of the Amazon Valley. 1889. Disponível em: <https://archive. org/details/narrativeoftraveoowall.>. Acesso em: 2 fev. 2014.

Recebido em: 13/05/14

Aceito em: 11/o8/14 


\section{GABRIELA REINALDO \\ gabriela.reinaldo@gmail.com}

Doutora em Comunicação e Semiótica pela Pontifícia Universidade de São Paulo, a PUC/SP, Gabriela Reinaldo é professora do Instituto de Cultura e Arte (ICA) da Universidade Federal do Ceará (UFC). Este artigo faz parte de sua produção no estágio pós-doutoral no Department of History of Art of the University of Cambridge - UK, onde permaneceu como Visitor Professor de agosto de 2013 a agosto de 2014. A pesquisa teve apoio da UFC e da Coordenação de Aperfeiçoamento de Pessoal de Nível Superior, Capes. 